


\section{Raturtwifienidaftlifie Elementarbiider.}

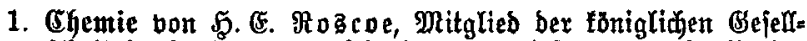

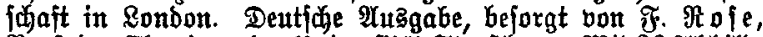
Prof. ber (Shemie an ber univerfität Strap̉burg. Dit 36 Abbils.

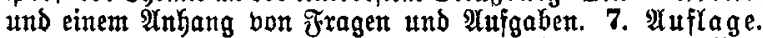
(Sebunder 80 Pfg.

2. Pyyjif von Balfour Stewaxt, Brofeffor ber Phyjte in

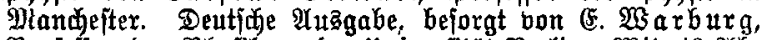

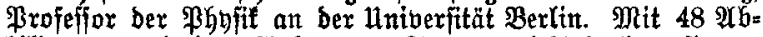
bild ungen und einem Ânhang bon fragen und $\mathfrak{A}$ ufgaben. 5. ver= bejferte $\mathfrak{A} u \mathfrak{f}$ age.

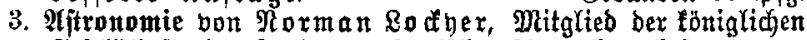

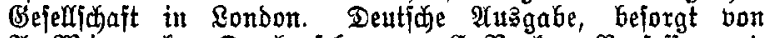

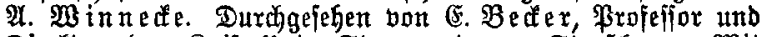

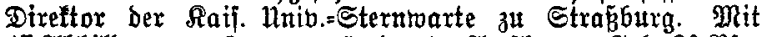
47 Ybbildurgen. 6. an veränderte $\mathfrak{A}$ fllnge. Beb. 80 Pfg.

4. Phyjifalijaje Gengraphie von 2 . Bet

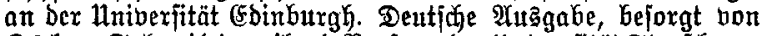

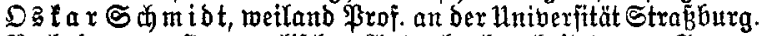

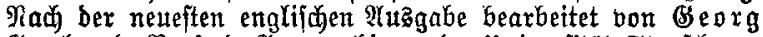

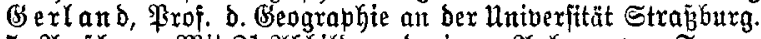

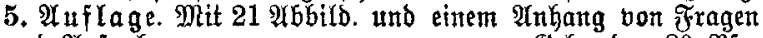
und $\mathfrak{A}$ ufgaben.

Gefunden 80 Pifg.

5. Sfeologie bot $\mathfrak{A}$. Beifie. Deutide $\mathfrak{A}$ Gagake, bejorgt von

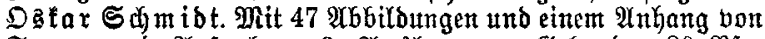

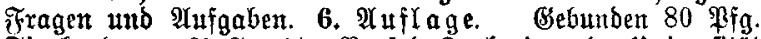

6. 7. Ticrtumbe von A. (5) oette, Frof. b. Boologite an ber Hniverfität

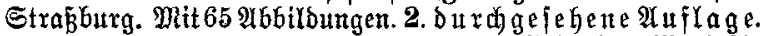
Gebunden $M$. 1.60 .

8. Botanil bon $\mathscr{A}$. be $\mathfrak{B a r y}$, toeiland $\mathfrak{B r o f . ~ a n ~ D e r ~ U n i b e r f i t a ̈ t ~}$

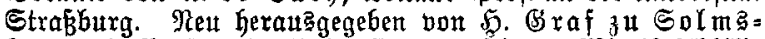

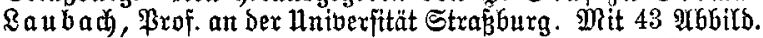
5. unveränderte $\mathfrak{A}$ aflage. Gebunden 80 Big.

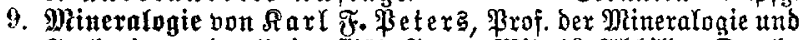

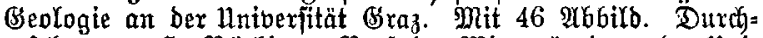

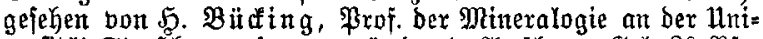
verjität Straj̧burg. 4. unveränderte $\mathfrak{A} u \mathfrak{l} \mathfrak{a}$ ge. Geb. 80 Big.

10. Phnjtologie oon $\mathfrak{M}$. Fofter, Profeffor an ber Untberfităt

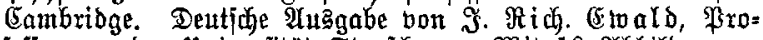

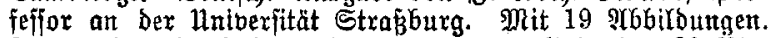
3. neu burdigefehene $\mathfrak{A}$ ufage. Sebunben 80 SPfg.

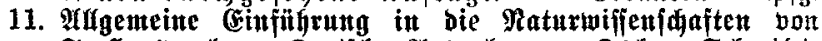

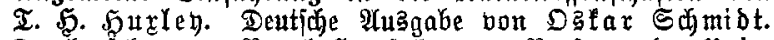

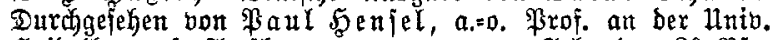
Soeibelberg. 4. $\mathfrak{A}$ uffage.

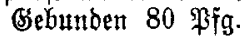




\title{
Maturwifienidajtlide EElementarbüder.
}

\author{
$\mathfrak{B} \mathfrak{d} \mathfrak{a} \mathfrak{n} \mathfrak{i} \mathfrak{l}$ \\ bont
}

\section{A. be Bary,}

weilats Rrofeffor at ser Univerfitüt Strapharg.

Reu herauşgegeben von

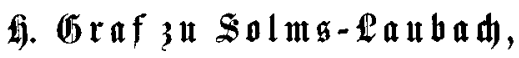

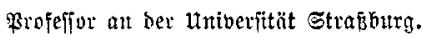

Dit abbitangen.

Fünite unweränberte $\mathfrak{A}$ ufflage.

\section{Strapburg.}

Berlag von $\mathfrak{R a r l}$ F. Trübner.

1899.

(überfebุung gaređ̆t vorbefalten.) 
